\title{
SOSIALISASI DAN PELATIHAN PENGGUNAAN ALAT PENGUPAS, PEMIPIL DAN PENCACAH TONGKOL JAGUNG DI KECAMATAN BULANGO ULU KABUPATEN BONE BOLANGO
}

\author{
Socialization And Training For Use Of Milling, Thresher And Corn Coconut Tools \\ In Bulango Ulu District Bone Bolango District
}

\author{
Evi Sunarti Antu ${ }^{1)}$,Yunita Djamalu ${ }^{2)}$,Burhan Liputo ${ }^{3)}$, \\ Sjahril Botutihe ${ }^{4)}$

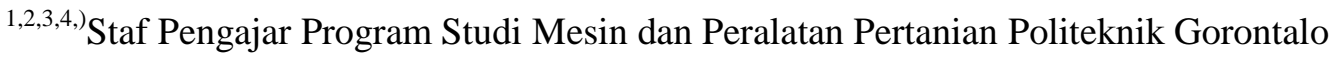 \\ Jl. Muchlis Rahim Desa Panggulo, Kec. Botupingge Kab. Bone Bolango, Provinsi Gorontalo \\ Email: evian@poligon.ac.id
}

\begin{abstract}
ABSTRAK
Desa Suka Makmur merupakan desa sasaran pada kegiatan Pengabdian Kepada Masyarakat. Dari hasil kegiatan pengabdian yang telah dilakukan, bahwa masyarakat desa suka makmur masih banyak yang belum tahu adanya mesin pengolah jagung 3 (tiga) fungsi yakni pengupas, pemipil dan pencacah tongkol dan kulit jagung. Mesin ini merupakan hasil penelitian dari Dosen Politeknik Gorontalo yang berkolaborasi dengan mahasiswa. Cara kerja mesin ini yakni, jagung yang sudah dipanen dijemur terlebih dahulu hingga kulit jagungnya kering. Jagung kering yang masih utuh dengan kulit dimasukkan kedalam hoper kemudian secara otomatis jagung tersebut akan dikupas. kemudian masuk kebagian pisau pemipil dan kemudian kulit jagung dan tongkol akan masuk kedalam pisau pencacah. Sehingga output dari alat ini adalah jagung yang sudah terpipil dan kulit beserta tongkol jagung yang sudah tercacah menjadi makanan hewan ruminansia. Harapan masayarakat sasaran yakni sekiranya alat ini bisa diusulkan menjadi program bantuan pemerintah yang akan disalurkan kepada mereka.
\end{abstract}

Kata Kunci : Jagung, pemipil, pengupas, pencacah

\begin{abstract}
Suka Makmur Village is a target village for Community Service activities. From the results of the service activities that have been carried out, many villagers like to prosper, many still do not know the existence of a 3 (three) function of a corn processing machine, namely peeler, sheller and cob counter and corn husk. This machine is the result of research from the Politeknik Gorontalo Lecturer who collaborated with students. The way this machine works is that the harvested corn is dried in the sun until the corn husk is dry. Corn is intact dry with the skin inserted into the hopper. Corn is intact dry with the skin inserted into the hopper. And then automatically the corn will be peeled then enter the shelling knife and then the corn husk and cob will enter into the chopper knife. So that the output of this tool is corn that has been squashed and the skin and corn cobs that have been chopped into ruminant animal food. The hope of the target community is that if this tool can be proposed as a government assistance program that will be channeled to them
\end{abstract}

Keywords: Corn, sheller, peeler, chopper 


\section{PENDAHULUAN}

Wilayah yang menjadi lokasi pelaksanaan pengabdian kepada masyarakat adalah Desa Suka Makmur kecamatan Bulango Ulu. Salah satu hasil pertanian didesa tersebut adalah jagung.Masyarakat di Desa Suka Makmur Kecamatan Bulango Ulu hanya menggunakan alat pemipil jagung dalam kegiatan pasca panen jagung.Jagung yang dimasukan kedalam pemipil jagung adalah jagung yang dikupas terlebih dahulu.Sehingga masyarakat masih membutuhkan tenaga manusia dalam hal mengupas kulit jagung.Selain itu, kulit dan tongkol jagung yang merupakan hasil limbah dari proses pasca panen jagung itu dibakar percuma padahal kulit dab tongkol jagung bisa menjadi makanan hewan ruminansia.

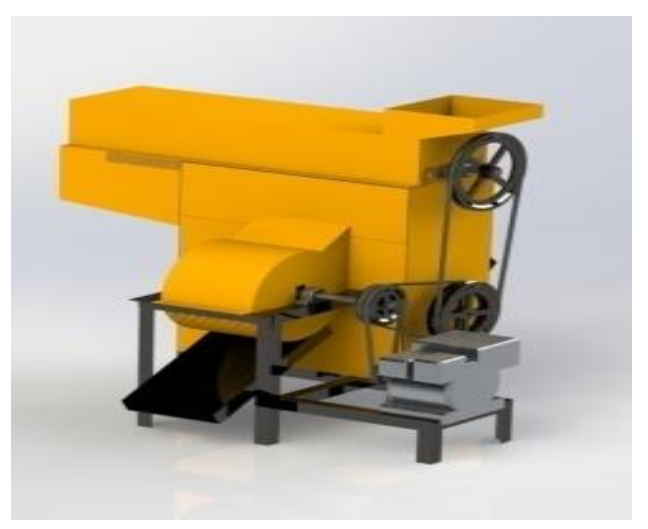

Gambar 1. Mesin pengupas, pemipil dan pencacah kulit serta tongkol jagung

Melalui kegiatan PKM ini akan diperkenalkan alat TTG pengupas, pemipil dan pencacah kulit serta tongkol jagung yang dapat digunakan petani di desa Suka Makmur pada pengolahan jagung pasca panen sehingga masyarakat petani jagung lebih bisa menghemat waktu pengolahan pasca panen dan dapat memanfaatkan limbah kulit serta tongkol jagung untuk mnjadi pakan ternak.

\section{Permasalahan Mitra}

a. Kondisi wilayah dan prioritas masalah

Kecamatan Bulango Ulu adalah desa yang mempunyai lahan pertanian sangat luas dengan komoditi utamanya adalah aren dan Jagung.Hasil panen desa ini di ekspor hingga ke luar daerah. Dalam pengolahan jagung pasca panen, masyarakat Bulango Ulu kebanyakan masih menggunakan cara tradisional dalam mengupas kulit jagung.
Karena alat yang beredar dimasyrakat yang berasal dari bantuan pemerintah adalah alat pemipil jagung.Jagung yang dimasukkan pada alat ini adalah jagung yang sudah dipisahkan dari kulitnya terlebih dahulu sehingga masyarakat harus mengupas terlebih dahulu jagung tersebut.Sehingga membutuhkan waktu tersendiri untuk mengupas jagung terlebih dahulu sebelum memasukkannya kedalam mesin pemipil jagung.Sehingga hal ini juga berpengaruh pada waktu pengolahan pasca panen yang semakin panjang. Selain itu juga, kulit an tongkol jagung belum dimanfaatkan dengan baik. Kebiasaan masyarakat didaerah tersebut adalah membakar kulit dan tongkol jagung hasil panen jagung tersebut.

Dari wacana diatas, maka persoalanpersoalan yang didapatkan dari masyarakat petani Kecamatan Bulango Ulu yakni sebagai berikut:

1. Proses pengolahan pasca panen jagung yang membutuhkan waktu dalam memisahkan kulit jagung dari tongkolnya karena masih dilakukan dengan cara manual

2. Petani jagung yang ada didesa sasaran belum mengenal alat 3 fungsi dalam pengolahan jagung yakni pengupas, pemipil dan pencacah tongkol serta kulit jagung.

b. Permasalahan prioritas

Masalah prioritas sebagai berikut :

1. Memperkanalkan dan mengajak masyarakat untuk menggunakan alat Teknologi Tepat Guna (TTG) dalam pengolahan pasca panen jagung sehingga lebih mempermudah dan mempersingkat waktu mereka dalam pengolahan hasil pasca panen jagung

2. Mendiseminasi alat pengupas sekaligus pemipil jagung di desa Suka Makmur kecamatan $\mathrm{Bu}$;ango Ulu sehingga ada semacam pertukaran informasi/ide antara perancang alat (dalam hal ini pihak POLIGON) dengan pengguna alat (petani) dengan harapan ada saran-saran yang bisa jadi masukan perbaikan alat untuk kedepannya.

\section{SOLUSI DAN TARGET LUARAN}

a. Solusi permasalahan

1. Dengan kegiatan PKM ini masyarakat desa sasaran mendapat pengetahuan dan 
bisa menggunakan alat pengupas sekaligus pengupas, pemipil serta pencacah kulit dan tongkol jagung sehingga bisa mempersingkat waktu yang digunakan dalam pasca panen jagung.

2. Dengan adanya diseminasi ini, pihak kampus akan mendapatkan informasiinformasi tambahan sesuai kebutuhan petani dan juga akan mendapatkan masukan perbaikan untuk produksi alat selanjutnya.

b. Luaran dan target capaian Jenis luaran kegiatan :

1. Publikasi jurnal nasionalberISSN

2. Peningkatan kualitas dan kesejahteraan masyarakat petani jagung di Desa Suka Makmur Kecamatan Bulango Ulu.

Target capaian yang akan dihasilkan :

1. Meningkatkan pengetahuan dan pemahaman masyarakat desa sasaran dalam penggunaan alat TTG dalam mengolah hasil panen

2. Menumbuhkan keberanian masyarakat dalam hal memberikan pendapat/masukan tentang kebutuhan akan alat TTG melalui diskusi, tukar perdapat saat diseminasi berlangsung.

\section{PELAKSANAAN KEGIATAN}

Kegiatan pengabdian kepada masyarakat dilaksanakan oleh tim dosen dari program studi Mesin dan Peralatan Pertanian Politeknik Gorontalo sesuai kebutuhan dalam masyarakat dan memberikan manfaat nyata baik secara langsung atau tidak langsung.

Kegiatan pengabdian kepada masyarakatini sendiri melibatkan para pihak internal maupun eksternal yang berkompeten.Adapun bentukkegiatan dalam pelaksanaan pengabdiankepada masyarakat dengan judul sosialisasi mesin pengupas, pemipil dan pencacah kulit serta tongkol jagung berupa sosialisasi dalam bentuk ceramah dan pelatihan penggunaannya alat.

Rangkaian pelaksanaan kegiatan adalah sebagai berikut :

Tim Dosen Pelaksana Kegiatan mengajukan proposal PKM kepada kepala UP2M. Setelah itu dengan sepengetahuan direktur dan ketua program studi, kepala UP2M mengeluarkan surat tugas bagi tim pelaksana PKM untuk melaksanakan kegiatan tersebut. Setelah pelaksanaan kegiatan, Tim Dosen pelaksana PKM melaporkan hasil kegiatan berserta bukti-bukti hasil kegiatan dalam bentuk laporan hasil kegiatan PKM.

\begin{tabular}{|c|c|c|c|}
\hline No & Kegiatan & Tanggal & Keterangan \\
\hline 1 & Persiapan & $\begin{array}{l}\text { 15 Juli } \\
2018\end{array}$ & \begin{tabular}{ll}
- & Pengaj \\
& uan \\
proposal \\
kegiatan \\
$-\quad$ & \multicolumn{1}{c}{ Pemb } \\
uatan & Modul \& \\
liflet & kegiatan \\
- & \multicolumn{1}{c}{ Memp } \\
ersiapkan \\
materi \\
kegiatan \\
\end{tabular} \\
\hline 2 & Pelaksanaan & $\begin{array}{l}16 \text { Agustus } \\
2018\end{array}$ & $\begin{array}{l}\text { Kegiatan } \\
\text { Sosialisasi dan } \\
\text { pelatihan Mesin } \\
\text { pengupas, } \\
\text { pemipil dan } \\
\text { pencacah kulit } \\
\text { serta tongkol } \\
\text { jagung didesa } \\
\text { Suka Makmur } \\
\text { Kecamatan } \\
\text { Bulango Ulu }\end{array}$ \\
\hline
\end{tabular}

HASIL DAN PEMBAHASAN

Hasil pelaksanaan PKM yang dilakukan oleh TIM PKM pada hari kamis, 16 Agustus 2018 di desa Suka Makmur kecamatan Bolango Ulu kabupaten Bone Bolango menunjukan bahwa :

1. Kegiatan yang dilaksanakan sangat bermaanfaat karena menambah pengetahuan masyarakat tentang alat teknologi tepat guna yang dapat membantu mereka dalam pengolahan pasca panen hasil lahan mereka.

2. Masyarakat sangat antusias dengan kegiatan PKM ini terlihat dari cara mereka memperhatikan penjelasan Tim dan memanfaatkan sesi Tanya jawab dengan sebaik-baiknya

3. Dengan keterbatasan waktu yang ada, mereka meminta untuk bisa melaksanakan acara yang sama dengan alat-alat TTG lainnya. 


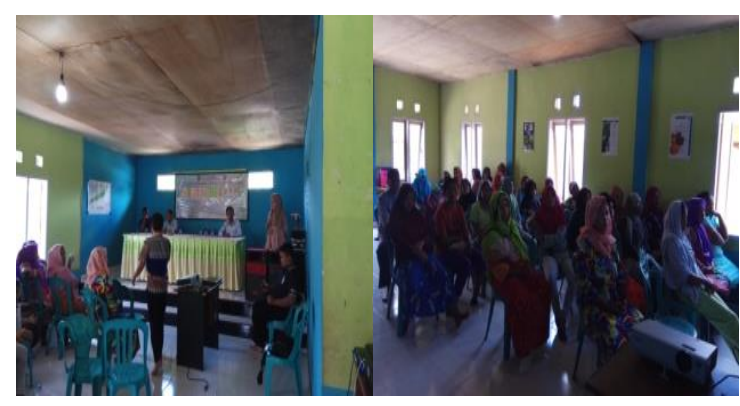

Gambar 2. Foto Kegiatan PKM pelaksanaan sosialisasi

Respon yang sangat baik dari masyarakat desa Suka Makmur membuat Tim PKM semangat dalam memberikan materi sosialisasi.Antusias masyarakat pada saat sesi Tanya jawab menunjukkan bahwa mereka memang sangat membutuhkan alat-alat TTG dalam pengolahan hasil lahan mereka.Masyarakat peserta dari kegiatan PKM ini memberikan saran agar alat-alat seperti ini agar dikoordinasikan dengan pemerintah dalam hal ini SKPD yang terkait agar bisa direkomendasikan untuk menjadi bantuan alat yang diberikan kepada masayarakat.

Masyarakat desa Suka Makmur dalam hal ini mereka yang mengikuti kegiatan PKM berharap Politeknik Gorontalo akan mengadakan kegiatan-kegiatan seperti secara berkelanjutan karena kegiatan seperti ini sangat bermanfaat bagi mereka.

\section{KESIMPULAN DAN SARAN}

\section{A. Kesimpulan}

Pengolahan jagung pasca panen di desa Suka Makmur kecamatan Bolango Ulu masih dilakukan secara tradisional.Adapun alat yang membantu mereka dalam pengolahan pasca panen yakni alat pemipil jagung.Untuk mengupas kulit jagung masih dilakukan secara manual.Selanjutnya tongkol dan kulit jagung dibakar layaknya sampah yang sudah tidak dapat digunakan lagi.

Melalui kegiatan PKM ini kami mensosialisasikan mesin dengan 3 fungsi sekaligus, yakni pengupas, pemipil dan pencacah tongkol serta kulit jagung yang nantinya bisa dijadikan sebagai pakan ternak.

Dengan melihat antusias dari masyarakat desa Suka Makmur saat kegiatan berlangsung, menandakan bahwa masyarakat sangat membutuhkan kegiatan seperti ini untuk meningkatkan wawasan mereka tentang alat teknologi tepat guna yang semakin hari semakin banyak inovasi-inovasi baru. Semoga kegiatan PKM ini akan membantu masayrakat dalam hal menambah pengetahuan mereka tentang alat TTG.

\section{B. Saran}

Pelaksaan kegiatan PKM ini diharapkan tetap dilakukan secara rutin terutama di desadesa terpencil jauh dari pusat kota. Beberapa saran yang disampaikan yakni :

1. Kegiatan sosialisasi alat TTG seperti ini ada baiknya dikoordinasikan dengan pemerintah dalam hal ini SKPD yang terkait agar bisa dijadikan rekomendasi bantuan alat dari SKPD kepada masayarakat desa

2. Kegiatan seperti ini lebih sering dilakukan didesa terpencil sehingga mampu menambah pengetahuan masyarakat

\section{DAFTAR PUSTAKA}

Agrowindo. 2015. Mesin Pemipil Jagung.

Diambil dari :

http://www.agrowindo.com/mesin-

pemipil-jagung-ppj03.html. (24

Januari 2017)

AgustianArie. 2013. Penanganan Pasca Panen Jagung. Diambil dari :http://arrieagustian.blogspot.co.id/201 3/02/penanganan-pasca-panenjagung.html. (23Januari 2017).

BKPPIJ (Badan Ketahanan Pangan dan Pusat Informasi Jagung). 2014. Potensi Pertanian Jagung. Bone Bolango.

BSN (Badan Standarisasi Nasional) . 2017. Detail SNI. Diambil dari : http://sisni.bsn.go.id/index.php/sni_ma in/sni/detail_sni/7768. (24 januari 2017)

Maksindo, 2017. Mesin pengupas kulit jagung. Diambil dari :

http://www.tokomesin.com/mesinpengupas-kulit-jagungcorpeeling.html. (22 Januari 2017).

Purwonodan R. Hartono., 2006. Bertanam Jagung Unggul. PenebarSawadaya. Jakarta.

Purwono dan Hartono. 2002. Bertanam Jagung. Kanisius, Jakarta. Roger S. Pressman, 2002. Rekayasa Perangkat Lunak Pendekatan Praktisi (Buku Satu), ANDI Yogyakarta. 